\title{
Образование для реформ: новые учащиеся, новые методы, новые оценки
}

Джим Барретт ${ }^{*}$

\section{Введение}

В течение последних нескольких десятилетий мы стали свидетелями появления множества новых особенностей в военном деле, видимо по большей части таких, которые не в нашу пользу. В этой статье я предлагаю вкратце рассмотреть четыре изменения, которые выдвинули новые требования к военному образованию, и затем подумать о том, что означают эти новые требования для специалистов в области военного образования. Это эссе заканчивается примером из реальной жизни, иллюстрирующим то, как волна перемен отражается на реформе военного образования в Республике Армения.

Четыре «новых» элемента, предлагаемых к рассмотрению, это:

1. Новый мир конфликтов и войн, к которому мы должны подготовить наших учащихся

2. Новый мир образования, в котором существуют обучение на продолжении всей жизни, электронное обучение и образование, сфокусированное на личности учащегося

3. Новые сети обучения, в том числе Европейская область высшего образования, инициатива НАТО по строительству оборонных институтов и Консорциум «Партнерства ради мира»

4. Реформа военного образования в новопоявившихся демократиях, охватывающая новые институции, новые программы и новое отношение.

Этот список далеко не полный, и дискуссия в сокращенном формате этой статьи в лучшем случае может быть только поверхностной, но он дает интригующие показатели того, как военное образование - этот чарующий базар, где встречаются мир военных и мир образования - справляется с вызовами программ военного образования, которые продолжают расширяться и которые уже охватывают некоторые весьма неожиданные области. Кто бы мог предположить пятьдесят лет назад, что разнообразие и гендерные подходы станут характерными особенностями профессионального военного образования? Такие темы находят место в программах отчасти из-за того, что они отражают современную чувствительность общества к правам человека, и отчасти из-за их оперативной полезности.

Джим Барретт - заслуженный профессор в отставке Королевского военного колледжа Канады. Эта работа является компиляцией вводных речей, произнесенных при открытии двух семинаров, состоявшихся в Армении 12-14 июня 2012 года. Четыре термина с определением «новые» были выбраны так, чтобы соответствовали темам семинаров. 


\section{Продолжающиеся изменения в условиях устойчивой культуры}

Профессия военного в некотором смысле является одной из самых устойчивых и вечных профессий на земле. Военная культура и военные традиции являются общими для разных стран и разных поколений. Но бизнес военной профессии является весьма текучим и постоянно меняющимся. Хотя военные традиции и ценности остаются теми же, каждая новая миссия порождает новые доктрины, новую тактику, новые уроки и новое мышление. Ежедневные репортажи о террористахсмертниках, об ударах, осуществленных беспилотными летательными аппаратами, и вирусах для кибервойн, напоминают нам о современной сложности старого бизнеса войны. Менее зрелищная, чем боевые операции, работа по строительству, управлению и поддержанию вооруженных сил тоже стала гораздо более сложной. Правительства требуют большей финансовой прозрачности. Приобретение вооружений, логистика и финансовый надзор требуют современных деловых умений. Общегосударственный и комплексный подход становятся все большей частью ткани оперативной работы, требуя целого ряда новых знаний и навыков.

Дело комплектования и поддержания современных и совершенных вооруженных сил в большой степени ложится на плечи военного инструктора и военного педагога, что означает, что инструкторы и специалисты по образованию несут ответственность за понимание того влияния, которое новые изменения в сфере обороны оказывают на военное обучение. И это означает не только отбор наиболее важных современных концепций и их включение в военные учебные планы. Сам характер учебных планов изменяется, так как многие из современных потребностей требуют более тщательного, более систематического и конечно, более академического подхода. В результате, в традиционной парадигме военной подготовки все больший вес приобретает компонент, ставший популярным как «профессиональное военное образование». ${ }^{1}$

Первый вопрос, который следует задать, это: как мы определяем программу военного образования? Наиболее очевидны технические соображения. Офицерам и солдатам нужны технические навыки, чтобы они могли использовать новые боевые способности. Более важным вызовом является вопрос, как использовать новые оружия и новую технику, имеющие и тактическое, и стратегическое применение. Наиболее ярким примером являются беспилотные летательные аппараты, оружие, которое может подчиняться ротному командиру на месте, или напрямую выполнять указания главы государства. Вопрос, который сопровождает использование беспилотников, это: перевешивает ли военная целесообразность политическую реакцию на удар беспилотников? ${ }^{2}$ Применение таких оружий - вот вопрос, который выходит далеко за пределы их технических возможностей и касается по-

1 Смотри, к примеру, Peter Foot, "Military Education and the Transformation of the Canadian Forces," Canadian Military Journal 7:1 (Spring 2006): 13-20.

2 Stephanie Nolen, "A Taboo Thought in Pakistan: What if Drones Work?," The Globe and Mail (Toronto) (17 November 2012). 
литической сферы. Чтобы применять такие оружия эффективно и разумно, солдатам понадобится нечто большее, чем просто тренировка. Им нужно образование.

И это приводит нас к третьему соображению: возросшая глубина или возросший уровень сложности обучения. Часто этот факт обозначается термином «образование» как контрапункт «практической подготовки», или улавливается в таксономии обучения. ${ }^{3}$ Практическая подготовка и образование представляют собой непрерывный спектр, в котором все деятельности по обучению располагаются на скользящей шкале между двумя крайностями «чистой» практической подготовки и «чистого» образования. Формирование солдат в сегодняшнем мире требует тренировок, предназначенных для выработки рефлективных действий в стрессовых ситуациях, и в то же время требует абстрактного изучения явлений и идей с целью ознакомиться с фундаментальными и универсальными принципами. Современное военное профессиональное развитие является смесью критического анализа, который дает нам образование, и инстинктов, которые может развить только тренировка и повторение. Ожидаемый результат военного образования - это способность к критическому мышлению перед лицом неизвестного, способность солдата к рациональной реакции в условиях непредсказуемой ситуации. ${ }^{4}$

Хотя многие могут думать, что будущее военного дела не является проблемой специалистов по образованию, но подготовка национальных вооруженных сил к реакции на нынешние и будущие угрозы определенно является задачей военных педагогов. На нас лежит ответственность за две вещи. Первая, это разработать и предоставить программу обучения, подходящую для современного солдата. Втоpoe, за что мы отвечаем, менее очевидное, но не менее важное, это создание и поддержка академической машины, которая позволит генерирование вооруженных сил, в том числе интеллектуалов в сфере обороны и военных мыслителей современных Клаузевицов, - которые наметят теоретическую рамку для будущей программы, и которые будут давать новым командирам логические и сбалансированные советы. Очень часто предполагается, что людей, которые будут отвечать за практическое обучение и образование, можно или назначить, или, может быть, нанять в любое время. Сегодня, более чем когда-либо, это не так. Истеблишмент военного практического обучения и военного образования надо растить и лелеять как наиболее важный элемент среды генерирования вооруженных сил.

\section{Новые инструменты для нового мира военного образования}

Пехотинцы академической машины - инструкторы и профессоры, эксперты по определенным дисциплинам, разработчики программ - борются не только с меняющимся военным миром, но и с новыми проблемами, которые появляются в

3 Смотри: Benjamin S. Bloom, Max D. Engelhart, Edward J. Furst, Walker H. Hill, and David R. Krathwohl, Taxonomy of Educational Objectives: The Classification of Educational Goals, Handbook I: Cognitive Domain (New York, NY: Longmans, Green, 1956).

4 Ronald G. Haycock, "Clio and Mars in Canada: The Need for Military Education," presentation to the Canadian Club, Kingston, Ontario (11 November 1999). 
системе самого образования. Школы и университеты, частные фирмы и правительственные организации, - все они почувствовали ударные волны двух очень сильных тенденций.

Первая, совершенно очевидная, это распространение Интернета и социальных медиа. Влияние этой революции проявляется везде вокруг нас. Реакцию образовательного сообщества можно увидеть в эксплозии числа курсов, предлагаемых через Интернет, или через такие мобильные платформы как iPhone. Военное образование тоже энергично ответило на эту тенденцию. Несмотря на сопротивление традиционных присутственных программ, военное онлайн образование сегодня в состоянии обучать и готовить большие когорты солдат за короткие периоды времени. Одним из первых примеров является онлайн курс «Введение в НАТО», впервые разработанный Колледжем обороны НАТО. 5 Этот короткий курс был спроектирован и скомпонован многонациональной командой меньше чем за год, и он остается доступным для военного персонала и других заинтересованных людей со всего света без ограничений. Важными ингредиентами - как и всегда - являются компетентные инструкторы или эксперты по определенным вопросам, которым помогают профессиональные дизайнеры учебных сайтов, и поддерживаемая система управления обучением (СУО). ${ }^{6}$ Онлайн обучение и электронное обучение сделали некогда невозможное просто дорогостоящим, и по мере того, как мы приобретаем опыт, некогда дорогостоящие формы образования станут доступными и даже обычными.

Вторая сильная тенденция, это огромный рост спроса на то, что мы начали называть «обучение в течение всей жизни». Стимулируемые быстрым развитием технологий, возросшим значением системных подходов в бизнесе и растущей популярностью последующего обучающего анализа, работающие взрослые люди всех возрастов ищут доступ к образованию для того, чтобы оставаться компетентными в своей работе, чтобы приобретать новые знания, необходимые для карьерного роста или для того, чтобы просто понять окружающий их мир. В прошлые времена представление о школе было «отстрелялся и забыл», место, куда посылали молодых, чтобы подготовить их к работе на всю жизнь. Сегодня работающие взрослые часто возвращаются в школу, чтобы идти в ногу с современными идеями, современными технологиями и современными инструментами. Отражение в этой обширной тенденции в военном деле можно увидеть в том, что сегодня мы называем «профессиональное военное образование» (ПВО). Возможно, уже никого не удивить тем, что ПВО часто оказывается вызовом для нашего конвенционального и консервативного мышления. Обучение в массовом масштабе является вызовом для идей, основанных на традиционной очной школе, и расширенный доступ младших чинов к обучению является вызовом для традиционной во-

5 Для дополнительных подробностей смотри сайт Колледжа обороны НАТО www.ndc.nato.int/education/courses.php?icode $=15$.

6 Смотри, к примеру, систему управления обучением ILIAS, которая поддерживает онлайн курсы, предлагаемые Консорциумом ПРМ: www.ilias.de/docu и www.isn.ethz.ch/eEducation/The-ISN-TACC/Advanced-Distributed-Learning-Working-Group. 
енной иерархии. Но, с другой стороны, эти особенности являются и настоящими возможностями.

Совместно эти две тенденции меняют лицо современного образования. Это изменение представляет собой нечто большее, чем просто предоставление курсов через Интернет. Гораздо более интересными оказываются часто ошеломляющие результаты экспериментов по электронному обучению, которые связаны с онлайн форумами и сообществами, с тестированием структуры новых курсов и с новыми концепциями обучения. Возможно, наиболее драматическая инновация - это массовый, открытый онлайн курс (МООК), ${ }^{7}$ который является онлайн курсом, предоставляемым консорциумом очень реномированных университетов тысячам студентам одновременно. ${ }^{8}$ Курсы бесплатны, все справочные материалы доступны онлайн и выставление оценок осуществляется другими студентами. ${ }^{9}$ Есть серьезные проблемы, которые еще надо решить, но университеты, вставшие на этот путь, настроены на серьезную работу. МООК, это только один из многих экспериментов в сфере образования, но нет сомнений, что школа радикально меняется. То, что остается неизменным, это потребность взрослых студентов, в том числе и военных студентов, в основательном и современном содержании курсов, в гарантировании качества и, часто, в сертифицировании. Пока неясно, к чему все это приведет, но понятно, что те, кто утверждают, что здесь нет ничего нового, или что персональное казарменное обучение является единственно приемлемой парадигмой, очевидно, не в курсе событий. А если говорить серьезно, они упускают те великолепные возможности, которые дают нам новые подходы.

Когда новые модели обучения применяются продуманно к подходящему содержанию, они освобождают ценное время и дорогостоящую учебную базу для очных занятий. Так как нельзя ожидать, что кто-либо в состоянии овладеть всем содержанием быстро меняющихся военных учебных планов, полезным подходом было бы определить основное существенное содержание, которое преподавалось бы в присутственных курсах, так сказать в казармах, и которое дополнялось бы широким спектром подходящих онлайн курсов, доступных определенным сегментам военной публики (или если необходимо, всему населению). Чтобы этот подход был успешным, современное военное образование должно создавать умение обучаться самостоятельно, оценивать критически и фильтровать важную информацию. Подход, ориентированный на учащегося, дает доступ к исключительно обширной военной учебной программе, которую легко адаптировать к националь-

7 Для более подробного знакомства с МООК смотри: www.youtube.com/watch?v=eW $3 \mathrm{gMGqcZQ}$ и и http:/www.nytimes.com/2012/11/04/education/edlife/massive-open-onlinecourses-are-multiplying-at-a-rapid-pace.html?pagewanted=all\&_r=0.

8 К примеру, один из консорциумов, Coursera, объединяет тридцать три университета, в том числе Колумбийский университет, Университет Калифорнии, Принстон, Стэнфорд, Университет Торонто, Университет Лондона, Политехнику Лозанны и Университет Мельбурна.

9 Курсы бесплатны, кроме как в случаях, когда студенты хотят получить после окончания курса академические кредиты. 
ным и локальным потребностям, и что более важно, к происходящим в военном деле изменениям.

Было бы ошибкой думать, что то, что работало в прошлом, будет служить нам хорошо и дальше. Во-первых, мир меняется настолько драматически и настолько быстро, что традиционные школы с их ограниченным потенциалом больше не в состоянии справляться. Во-вторых, наши молодые рекруты, которые выросли с Интернетом и смартфонами, больше не будут терпеть наш устаревший способ делать бизнес. У военного образования практически нет выбора, кроме как адаптироваться к окружающему его миру и к его дигитализированным гражданам.

\section{Сети для обучения}

Если бы мы захотели охарактеризовать результаты Интернет революции одним словом, этим словом вполне могло бы быть слово «связанность». Мы все стали связанными, почти не осознавая того, через все более доступную глобальную коммуникационную сеть. Эта связанность так же находит и более официальное и институциональное выражение. Болонские соглашения установили общие университетские стандарты в Европейском пространстве высшего образования. Подобными соглашениями были установлены и стандарты для профессионального образования. ${ }^{10}$ Студент может проходить курсы - присутственные или онлайн - в нескольких европейских университетах и колледжах, чтобы получить европейские кредиты. Похожие сети существуют и в военном образовании. Многие европейские штабные колледжи восприняли образовательные стандарты Болонского процесса, ${ }^{11}$ а инициатива европейского военного Эразмуса способствует обмену молодыми офицерами, профессорами и даже курсами между военными образовательными институциями с целью установить общие академические стандарты, и в перспективе, общую структуру обороны и безопасности. ${ }^{12}$

На стратегическом уровне ежегодно проводится Конференция Начальников военных учебных заведений НАТО, на которой обсуждаются текущие проблемы военного образования. ${ }^{13}$ Эта группа, первоначально состоявшая только из членов НАТО, сейчас включает и страны из инициативы «Партнерство ради мира» (ПРМ) ${ }^{14}$ Средиземноморского диалога ${ }^{15}$ и Стамбульской инициативы сотрудничества. ${ }^{16}$ На более населенном рабочем уровне мы находим мероприятия НАТО/ ПРМ из Плана Действий Партнерства по Строительству Оборонных Институтов

10 Смотри: http://www.ehea.info и http://ec.europa.eu/education/lifelong-learning-policy/ ecvet_en.htm.

11 Польша и Румыния являются хорошими примерами такой политики.

12 Смотри, к примеру, www.emilyo.eu/.

13 Смотри: www.ndc.nato.int/news/current_news.php?icode=285.

14 Информация о предпосылках доступна на www.nato.int/cps/en/natolive/topics_50349.htm.

15 Для более детальной информации смотри www.nato.int/cps/en/natolive/topics_52927.htm.

16 Смотри www.nato.int/cps/en/natolive/topics_52956.htm. 
(ПДП-СОИ), который должен оказать помощь странам-партнерам в реформировании их оборонных институтов, в том числе и институций военного образования. ${ }^{17}$

Руководят инициативой ПДП-СОИ и обеспечивают ее две организации, которые близко сотрудничают. Отдел Политических дел и политики в сфере безопасности Международного секретариата НАТО опирается на ad hoc сети доноров, которые предлагают свои услуги через «клиринговые дома», представляющие собой встречи, организуемые для сочетания потребностей стран-партнеров с компетентностью доноров. Консорциум «Партнерства ради Мира» Военных Академий и Институтов Исследований в Сфере Безопасности (Консорциум ПРМ) является более официальной сетью, включающую свыше 300 институций, которые предоставляют членов для шести Рабочих групп Консорциума, а так же и для неформальной сети НАTO ${ }^{18}$ Рабочая группа по развитию образования является главным донором проекта ПДП-СОИ. ${ }^{19}$

Есть три основных вида деятельности по проекту ПДП-СОИ, которые обеспечивают реформу военного образования. Первый, это разработка серии Примерных учебных планов. Текущая работа в этой области сейчас направлена на разработку Примерной учебной программы для профессионального образования сержантов. ${ }^{20}$ Второй элемент, это Программа специалистов по образованию для преподавательского состава военных образовательных институций стран-партнеров, направленная на популяризирование новых подходов к проектированию содержания курсов, к преподаванию и обучению, в том числе и к применению самых современных методов учебы. Третий элемент, это Программа Совершенствования Образования в Сфере Обороны, или ПСОСО, которая представляет собой серию визитов в страну-партнера многонациональных рабочих групп, предоставляющих экспертные советы и поддержку усилиям страны-партнера, направленных на реализацию реформ военного образования в соответствии с Индивидуальным Планом Действий Партнера (ИПДП) или Планом Действий по Членству (ПДЧ). К моменту написания этой статьи уже в десяти странах рутинно проводятся или планируется провести визиты групп ПСОСО.

Эти три сферы деятельности действительно охватывают большую сеть поддерживающих стран, институций и личностей, которые знакомят партнеров с современными концепциями и лучшими практиками. Менеджмент реформ может начаться руководством сверху, но на каждом уровне реализации лидеры и менеджеры должны интерпретировать и фильтровать это руководство для того, чтобы сформировать свою реакцию. Знакомство с новыми идеями в военном образовании помогает формированию кадрового состава военных лидеров и менеджеров, которые понимают смысл и перспективу изменений и у которых есть мотивация

17 Больше информации об инициативе ПДП-СОИ можно найти на www.nato.int/cps/ en/natolive/ topics_50083.htm.

18 Смотри веб-сайт Консорциума на https://pfpconsortium.org/node/5/about.

19 Смотри статью Джона Берри в этом номере.

20 "NATO Launches Reference Curriculum for Defense Institution Building," доступно на: www.nato.int/cps/en/natolive/news_57397.htm. 
для их реализации. Последним компонентом является сама сеть и модель сети установление связей между институциями военного образования, установление связей с гражданскими институтами, расширение и поддержка сети. Это сеть, чьи взаимосвязи выходят за пределы любой текущей задачи и будут существовать долго после ее завершения. Для Консорциума ПРМ остаются актуальными две проблемы: координирование и финансирование функционирования его Рабочих групп, и вторая - нахождение подходящего способа поддерживать многонациональный характер его исключительной сети стран, институций и личностей.

\section{Вызов Армении}

Первый визит по программе ПСОСО в Республику Армения был в мае 2008 года. Посетители увидели маленькую страну, зажатую на пересечении трех старых империй, с восточной и западной границами, закрытыми для торговли, и тлеющим «замороженным» конфликтом с ее соседом, Азербайджаном. Хотя Армения хотела установить более близкие связи с Европой и Западом, она оставалась союзником России и не стремилась к членству в НАТО. Население Армении около 3.5 миллионов жителей, хорошо образовано, и грамотность приближается к 100 процентам.

Армянские вооруженные силы, по большей части, организованы по старой советской модели, и основные единицы - это полки, состоящие из механизированных пехотных рот. ${ }^{21}$ Существует профессиональный офицерский корпус, но нет корпуса сержантов, большинство солдат служит по призыву. Военную реформу в Армении движет желание создать современные вооруженные силы, соответствующие обстоятельствам и стратегической ситуации, в которой находится Армения - «новая армия для новой Армении». Но для этой страны реформа не простая проблема. Замороженный конфликт в Нагорном Карабахе постоянно вынуждает страну сосредотачиваться на непосредственных потребностях самообороны. Но даже с учетом этого, молодая республика стремится к перспективным и более фундаментальным решениям для обеспечения своей безопасности и обороны.

За исключением создания оперативно совместимой с НАТО бригады миротворцев, реформа в секторе обороны Армении развивалась медленно. В какой-то степени причиной тому являлось отсутствие в Армении институций военного образования, которые порождали бы новое мышление и формировали бы программу реформ. Армения начала жизнь новой независимой республики без каких-либо военных учебных заведений. Военные академии, штабные и командные колледжи, которые являются основными институциями развитой системы военного образования, были расположены в других местах Советского Союза. ${ }^{22}$ Учреждение в 1993 году Военного института имени В. Саргсяна и Военного авиационного института было большим достижением, но в 2012 году образовательного потенциала для обучения офицеров среднего и высшего уровня все еще не хватает. Для Рес-

21 Каждый полк эквивалентен примерно трем батальонам.

22 Смотри статью Хаика Котанджияна по этому вопросу. 
публики Армения это означает, что создание собственного нового командного и штабного курса, а затем и академии, в которой проводить эти курсы, является вопросом особой важности.

Первой задачей посещения экспертов ПСОСО было помочь советами при создании Концепции образования в сфере обороны, и при этом подтвердилась необходимость организовать командно-штабной курс. Появившийся в результате проект стал основным фокусом работы экспертов ПСОСО. Новая учебная программа, представляющая собой фундаментальный переход от ограниченной командной доктрины к доктрине, которая больше напоминает западное командование миссий, означала бы для армянских вооруженных сил окончательный отказ от советской модели. Более того, новую программу следовало разработать в соответствии со стандартами Болонского процесса под совместным руководством министра обороны и министра образования. По этому критически важному проекту, пилотный курс должен начаться в 2013 году, а основной командно-штабной курс - в 2014 году.

Организация современного курса для старших офицеров является только началом. Он приведет к реформам, но так же вызовет немалое напряжение среди консервативных военных. Другие проекты реформ - в первую очередь учреждение корпуса профессиональных сержантов - вероятно будут иметь не менее драматические последствия. Представители западных стран иногда не понимают насколько трудными могут быть такие изменения. Один армянский полковник сказал нам, что каждый офицер, который родился в советские времена страдает как бы раздвоением личности. Одна личность остается верной армии в которой он начал свою службу и в чьих военных традициях он был воспитан. Другая личность побывала в Западной Европе и в Соединенных Штатах Америки и начала понимать, что армия в которой он служит пока не является современной армией. Таким образом он является двумя людьми - советским офицером и современным офицером - и каждый день эти две личности борются друг с другом, чтобы найти армянское решение.

Далее, проект ПСОСО продолжился как расширенный доверительный диалог с коллегами - представителями министерства обороны и Военного института - задавались вопросы и давались ответы с целью раскрыть философию и концепции, которые лежат в основе современной западной военной практики. Тесно направленные дополнительные проекты и мероприятия придали содержание этому продолжающемуся диалогу. Армения учится, в частности у новых стран-членов НАТО, которые прошли тот же путь на несколько лет раньше. Таким образом, сотрудничество по программе ПСОСО обеспечивает получение национального и профессионального опыта широкого спектра, и предлагает возможности для дублирования преподавателей, посещений экспертов, семинаров и приглашений для визитов в военные учебные заведения других стран. Для Республики Армения, это исключительно ценный ресурс, так как она строит свою военную образовательную систему не для прошедшего и не для сегодняшнего дня, а для завтрашнего. 


\section{Заключение}

Республика Армения является превосходной иллюстрацией меняющегося мира военного образования. Это новое независимое государство поддерживает тщательное равновесие между Востоком и Западом, поддерживая хорошие отношения и военный союз с Российской федерацией и в то же время стремится к обогащению своих отношений с Европой и НАТО. Западную модель надо адаптировать к армянской ситуации с определенной чуткостью. В итоге, Армения выберет то, что ей нужно из множества западных возможностей, с которыми она ознакомится, принимая решение, что лучше всего подходит для будущего Республики. В двух словах, реформа военного образования есть, как и должно быть, руководимый Арменией проект, осуществляемый с поддержкой и поощрением Запада.

На Западе, большая волна энтузиазма относительно военного образования, которая поднялась после распада Советского Союза, уже начала спадать. На Востоке, важность военного образования не уменьшилась в той же степени. На то есть основания, и не последнее из них это европейский проект, направленный на интегрирование военного и гражданского образования и использование во все большей степени гражданских ресурсов для обучения вооруженных сил. Другим способствующим фактором является интенсивная интроспекция и анализ, которые новые независимые государства провели с целью определить в чем их потребности в новой среде безопасности, и какие способности они могут себе позволить. «Старый Запад» может многому научиться от оценки новых моделей военного образования, которые появляются в Восточной Европе и Средней Азии. Эти новые системы могут быть еще незрелыми, или еще не полностью развитыми, но они часто задуманы интересным образом и хорошо адаптированы к местным условиям. Мы можем научиться многому друг у друга. 


\section{Литература}

Bloom, Benjamin S., Max D. Engelhart, Edward J. Furst, Walker H. Hill, and David R. Krathwohl. Taxonomy of Educational Objectives: The Classification of Educational Goals, Handbook I: Cognitive Domain. New York, NY: Longmans, Green, 1956.

CIA World Factbook - Armenia., 2012.

Foot, Peter. "Military Education and the Transformation of the Canadian Forces." Canadian Military Journal 7, no. 1 (2006): 13-20.

Haycock, Ronald G.. Clio and Mars in Canada: The Need for Military Education. Kingston, Ontario: presentation to the Canadian Club, 1999.

NATO Launches Reference Curriculum for Defense Institution Building. NATO, 2009.

Nolen, Stephanie. "A Taboo Thought in Pakistan: What if Drones Work?" The Globe and Mail (Toronto) (2012). 